\title{
INTRODUÇÃO À PROJETOS DE ROBÓTICA UTILIZANDO O ROBÔ CURUMIM
}

Thiago F Dornelles - thiago.fdornelles@gmail.com

Isaque F M da Silva - isaquefernando10@gmail.com

Sandro R Dias - sandro@decom.cefetmg.br

André R da Cruz - dacruz@cefetmg.br

Joana A P F Avelino - joanaforte@cefetmg.br

Centro Federal de Educação Tecnológica de Minas Gerais/Campus II

Avenida Amazonas, 7675, Nova Gameleira

CEP 30510-000 - Belo Horizonte - Minas Gerais

Resumo: Visando a diminuição da evasão do curso de Engenharia de Computação do CEFET-MG campus II, o Programa de Educação Tutorial de Engenharia de Computação(COMPET), dentre algumas medidas, propôs a realização de projetos de robótica juntamente com os alunos do primeiro período do curso. Dentre os projetos escolhidos, o Curumim foi selecionado pelo grupo e contou com um planejamento prévio para reaver o funcionamento do robô com foco no processo de aprendizado dos alunos. A partir da experiência, os alunos receberam novas perspectivas sobre as falhas $e$ as possibilidades de soluções mediante as mesmas. Também foi possivel verificar os erros com o robô e definir um novo projeto como alvo.

Palavras-chave: COMPET, Robótica, Curumim, Computação.

\section{INTRODUÇÃO}

A evasão escolar no ensino superior é um grave problema que se apresenta para o sistema educacional brasileiro e internacional (SILVA FILHO et al, 2007). A principal causa identificada pelos membros do COMPET é a alta carga de matérias de exatas no início do curso de Engenharia de Computação do CEFET-MG campus II.

Os projetos de robótica fazem parte de um conjunto de iniciativas do COMPET para incentivar os alunos com materiais mais práticos que envolvem a ementa do curso. Tais projetos são liderados por um aluno membro do COMPET e contam com a participação de 5 (cinco) alunos do primeiro período, onde o foco principal é a interação com um projeto robusto e interdisciplinar que busca exibir a abrangência da área de computação.

A conclusão de um curso de graduação é um desafio para qualquer aluno, pois ele recebe uma liberdade maior, além de maiores cobranças o que exige naturalmente uma boa administração do tempo e disciplina para o cumprimento das tarefas. Diversos fatores podem influenciar o abandono de um aluno do curso, desde falta de interesse até um alto nível de cobrança. Para aumentar o interesse do calouro com o curso e, portanto, diminuir a taxa de evasão do mesmo, foi pensado o projeto de robótica, para melhorar o engajamento dos novatos com o curso. Para os membros do COMPET, o projeto é crucial para entender melhor as dificuldades e peculiaridades de cada aluno, para assim tornar o curso melhor para todos. 
Alguns estudos observaram que a programação de computadores tem sido o recurso mais utilizado para o desenvolvimento do pensamento computacional. Conforme sua análise, os autores verificaram que "a programação tem se revelado uma abordagem habitual tanto para disseminar o pensamento computacional como para avaliar a aprendizagem de pensar computacionalmente por parte do aluno" (ARAÚJO; ANDRADE; GUERRERO, 2016, p. 1153).

Acompanhando esta abordagem foi realizado pesquisas qualitativas de projetos que de alguma forma colaboram com o objetivo de incentivar o aluno, dentre essas pesquisas, o robô Curumim se torna uma excelente opção, já que sua criadora, a empresa XBot, é conhecida por seus projetos robustos porém educacionais, o que viabiliza a utilização dos seus produtos como referências para aprendizado de robótica e organização (XBot, 2018). Dessa forma o projeto se baseou no funcionamento e programação do robô objetivando a apresentação de um conteúdo avançado e interdisciplinar para os novos alunos do curso. Cabe ressaltar a importância em desenvolver a autonomia dos alunos, levá-los a refletir de modo mais profundo acerca da tecnologia e seus impactos no nosso dia a dia, além de introduzi-los no Pensamento Computacional (COSTA, CAMPOS, GUERRERO, 2016; WING, 2014).

O objetivo principal do robô Curumim é entregar um projeto que possa ser montado juntamente dos alunos, podendo este se locomover, conta com um sensor infravermelho, uma câmera, comunicação sem fio e um local para acoplar outras funcionalidades. Ainda oferece uma programação simplificada utilizando blocos para quem está iniciando em lógica de programação, também podendo ser programado com uma linguagem propriamente dita para usuários mais avançados.

\section{PLANEJAMENTO}

Para que a atividade ocorresse foram definidos os monitores de cada projeto em uma reunião antes do início do semestre letivo. Após a definição os monitores iniciaram uma pesquisa, de cunho qualitativo, para montar sua base de informações sobre os robôs, já que muitos deles não conheciam os dispositivos que iriam trabalhar. Os projetos se dividiram em dois viés diferentes, onde um foi a montagem de robôs utilizando kits LEGO e Arduino, e outros tinham como objetivo verificar, iniciar e programar o funcionamento de alguns robôs disponibilizados pelo LSI (Laboratório de Sistemas Inteligentes) do CEFET-MG. O projeto Curumim se encaixa na segunda abordagem sendo um robô que já funcionou em alguns momentos, porém ficou ocioso por um longo período de tempo, o que motivou a sua colocação nos projetos de robótica objetivando-se recolocar o robô em funcionamento.

Para alcançar o objetivo supracitado, o membro líder definiu e organizou as reuniões com os focos de conhecer o robô, preparar o ambiente de programação, programar o robô e testar a programação implementada. Como os integrantes dispunham de 8 encontros, foi definido para cada etapa o período de 2 encontros. É durante a construção do projeto que o aluno vai atribuindo significados e construindo seu próprio método de resolução dos problemas, segundo seu estilo de aprendizagem (ALMEIDA, 2000).

Dessa forma os alunos eram instruídos em cada etapa com o objetivo da conclusão e garantia de aproveitamento. Para o acompanhamento foram utilizados tabelas e formulários de gerenciamento de atividades que eram preenchidos ao término de cada encontro detalhando o que foi realizado e como foi realizado. Durante a execução das atividades todos os alunos se envolveram em todas as partes já que o grupo realizava uma mesma atividade contando com o foco e dedicação de todos os membros. 
"Os desafios para formar hoje o engenheiro do amanhã"

\section{Evento On-line}

\begin{tabular}{|l|l|l|l|}
\hline & Data & Atividades Planejadas & Atividades Realizadas \\
\hline Encontro 1 & & \\
\hline Encontro 2 & & \\
\hline Encontro 3 & & \\
\hline Encontro 4 & & \\
\hline Encontro 5 & & \\
\hline Encontro 6 & & \\
\hline Encontro 7 & & \\
\hline Encontro 8 & & \\
\hline
\end{tabular}

Figura 1: Exemplo de planilha de gerenciamento

Já que o robô foi entregue montado para o início do projeto não fez-se necessário a reserva de materiais para montagem. Para a programação previamente foi testada a instalação do ambiente de programação.

\section{AVALIAÇÃO}

O processo de avaliação se deu através do retorno dado pelo membro líder do grupo ao final de cada encontro em que realizava uma entrevista com os alunos para garantir que o conhecimento foi assimilado. Ao final de cada reunião o membro responsável documentava o andamento do projeto juntamente com uma visão crítica daquilo que foi alcançado e das metas para o próximo encontro dado o ponto atual. Toda semana por meio de uma reunião tais informações eram avaliadas pelos próprios líderes e também pelos tutores com objetivo de validar decisões sobre o andamento do projeto.

\section{RESULTADOS}

Durante o andamento do projeto e com as avaliações realizadas fez-se necessário a mudança de objetivos definidos no início do projeto. Por problemas técnicos apresentados pelos robôs não foi possível realizar a conexão com o computador. Para verificar isso, os integrantes utilizaram os encontros restantes para abrir o robô e verificar as conexões internas com o objetivo de encontrar o possível causador do problema.

Dessa forma, somente os passos iniciais de reconhecimento do robô e preparação do ambiente de programação foram bem sucedidos e por fim do tempo hábil do projeto não foi possível ir a fundo na investigação do causador do problema, sendo o projeto final a escrita de um manual interno sobre todos os testes e verificações realizadas no robô até o término do projeto com os alunos. Porém, vale ressaltar que durante a execução do projeto e na investigação do erro, fez-se necessário solicitar ajuda a alguns professores com conhecimentos de robótica para que houvesse um desdobramento dessa etapa.

\section{CONSIDERAÇÕES FINAIS}

Percebemos que o objetivo do projeto foi alcançado com sucesso, os alunos demonstraram grande interesse em ir até o fim apesar do resultado inesperado com o robô apresentando problemas. A falha foi encarada pelos alunos como um fator motivador para trabalhar além do planejado, porém com o tempo e o auxílio do tutor esse insucesso foi encarado com um processo necessário e natural dentro da área de engenharia. Tal ensinamento inspirou não somente os alunos quanto também os membros do COMPET que 


\section{Evento On-line}

acompanhavam o projeto. Portanto, pode-se concluir que a atividade foi importante para os alunos já que os ensinou a lidar com a falha e as possibilidades que ela oferece. Aos membros do PET foi notório o ensinamento quanto a necessidade de persistência e também a forma de se encarar os problemas, já que o seu posicionamento influenciava diretamente os alunos integrantes.

A falha possibilitou a verificação de diversos defeitos nos robôs o que abriu a possibilidade para utilização das peças sobressalentes em um novo projeto tendo toda a parte de controle sendo confeccionada novamente. Dessa forma, uma sugestão de continuação do projeto é a execução desta etapa pelos membros em um momento futuro.

\section{Agradecimentos}

Agradecemos ao CEFET-MG pelo apoio e fomento do grupo PET, através da Diretoria de Graduação, para a realização da atividade aqui descrita, bem como o auxílio financeiro para a participação e apresentação deste trabalho no COBENGE 2020.

\section{REFERENCIAS}

XBot, XBot Br. Aprimorando o ensino com tecnologia. Brasil, 2018. Disponível em: http://www.xbot.com.br/. Acesso em: 16 dez. 2018

Campus II, CEFET-MG: Homepage do campus II do CEFET-MG. Disponível em: http://www.campus2.cefetmg.br/. Acesso em: 23 out 2018

DECOM, CEFET-MG: Homepage do curso de Engenharia de Computação Campus 2. Disponível em: http://www.decom.cefetmg.br/. Acesso em: 16 dez. 2018

COSTA, E. J. F.; CAMPOS, L. M. R. S.; GUERRERO, D. D. S.. Pensamento computacional a Educação Básica: uma análise da relação de questões de Matemática com as competências do Pensamento Computacional. In: CONGRESSO BRASILEIRO DE INFORMÁTICA NA EDUCAÇÃO, 5., 2016, Uberlândia. Anais dos Workshops do V Congresso Brasileiro de Informática na Educação. Uberlândia: Cbie 2016, 2016. p. 1060 1069.

ARAÚJO, A. L. S. O.; ANDRADE, W. L.; GUERRERO, D. D. S.. Um mapeamento sistemático sobre a avaliação do Pensamento Computacional no Brasil. In: CONGRESSO BRASILEIRO DE INFORMÁTICA NA EDUCAÇÃO, 5., 2016, Uberlândia. Anais dos Workshops do V Congresso Brasileiro de Informática na Educação. Uberlândia: Cbie 2016, 2016. p. 1147 - 1158.

ALMEIDA, M. E. B. de. ProInfo: Informática e formação de professores. Ministério da Educação, Secretaria de Educação a Distância. v. 1, 2000.

SILVA FILHO, R; MONTEJUNAS, P.; HIPÓLITO, O.; LOBO, M A Evasão no Ensino Superior Brasileiro. Caderno de Pesquisa. v. 37, n. 132, São Paulo, set/dez 2007.

\section{ANEXOS}




\section{CCOBENGE \\ "Os desafios para formar hoje o engenheiro do amanhã" \\ Ol a 03 de dezembro Evento On-line}

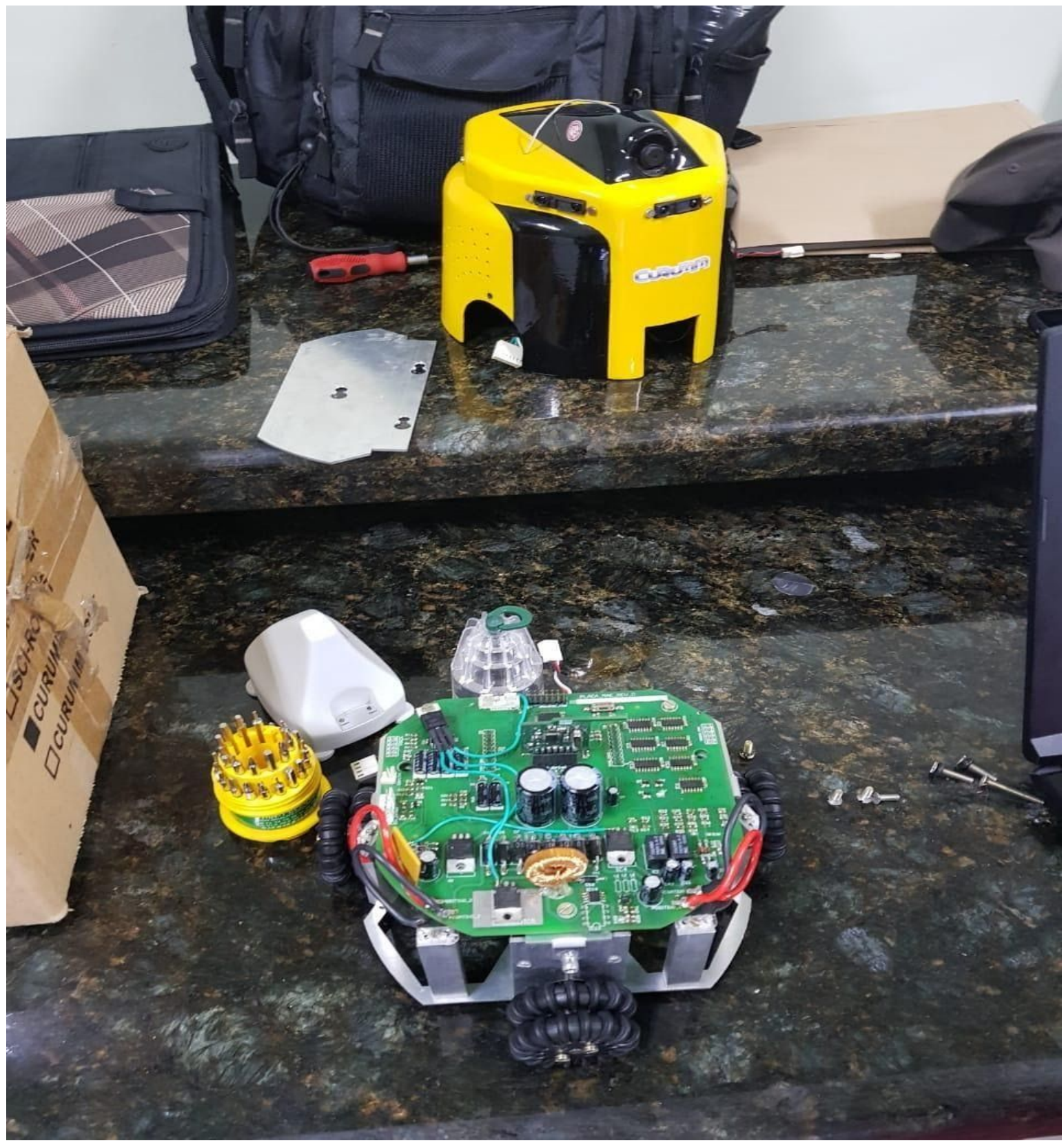

Figura 2: Componentes do robô Curumim. 


\section{(G) COBENGE $2020 \begin{aligned} & \text { de Educação em Engenharia } \\ & \text { da ABENGE }\end{aligned}$ \\ Ol a 03 de dezembro Evento On-line \\ "Os desafios para formar hoje o engenheiro do amanhã"}

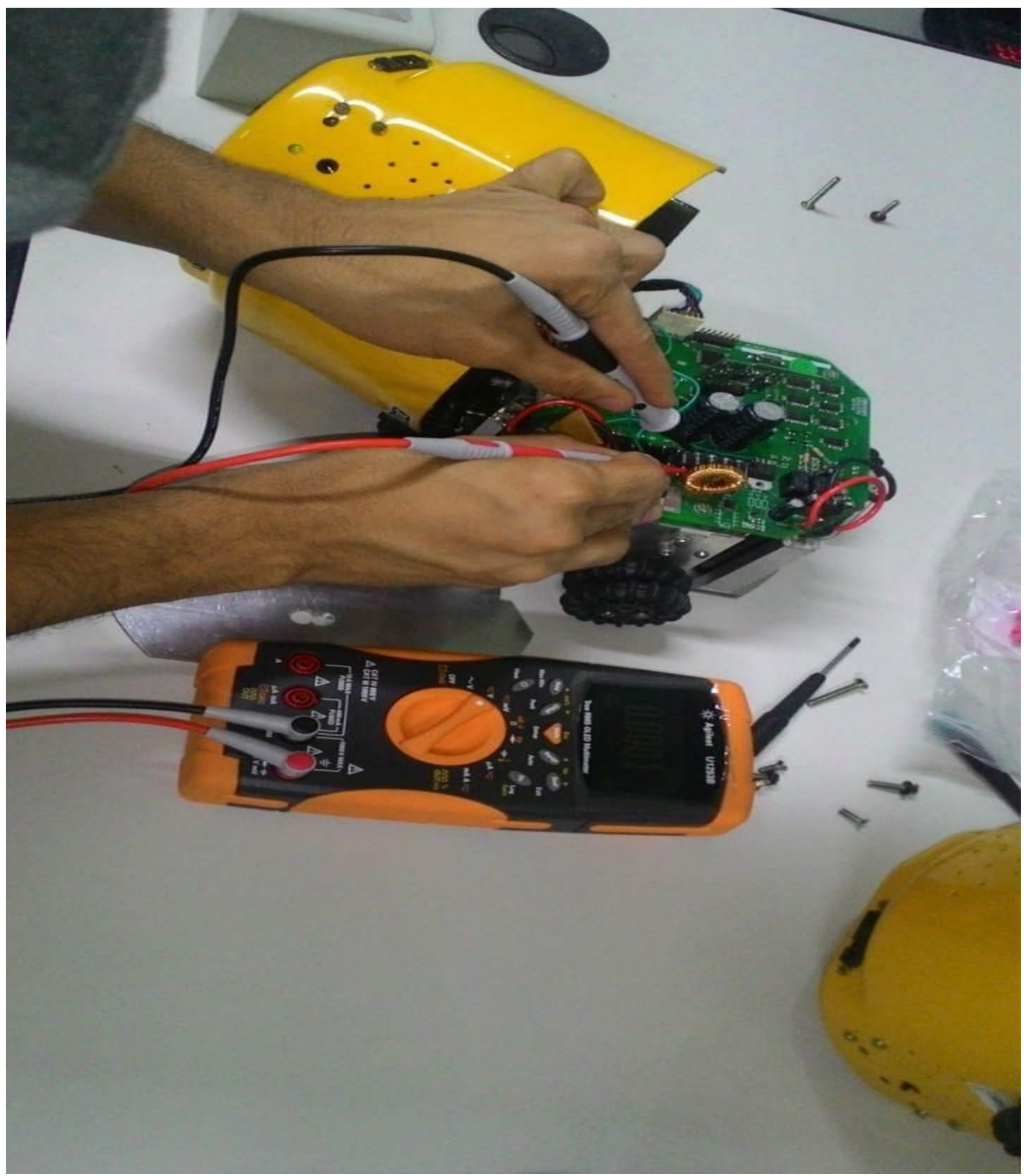

Figura 3: Teste de condutividade dos componentes do robô. 


\section{COBENGE \\ "Os desafios para formar hoje o engenheiro do amanhã" \\ Ol a 03 de dezembro Evento On-line}

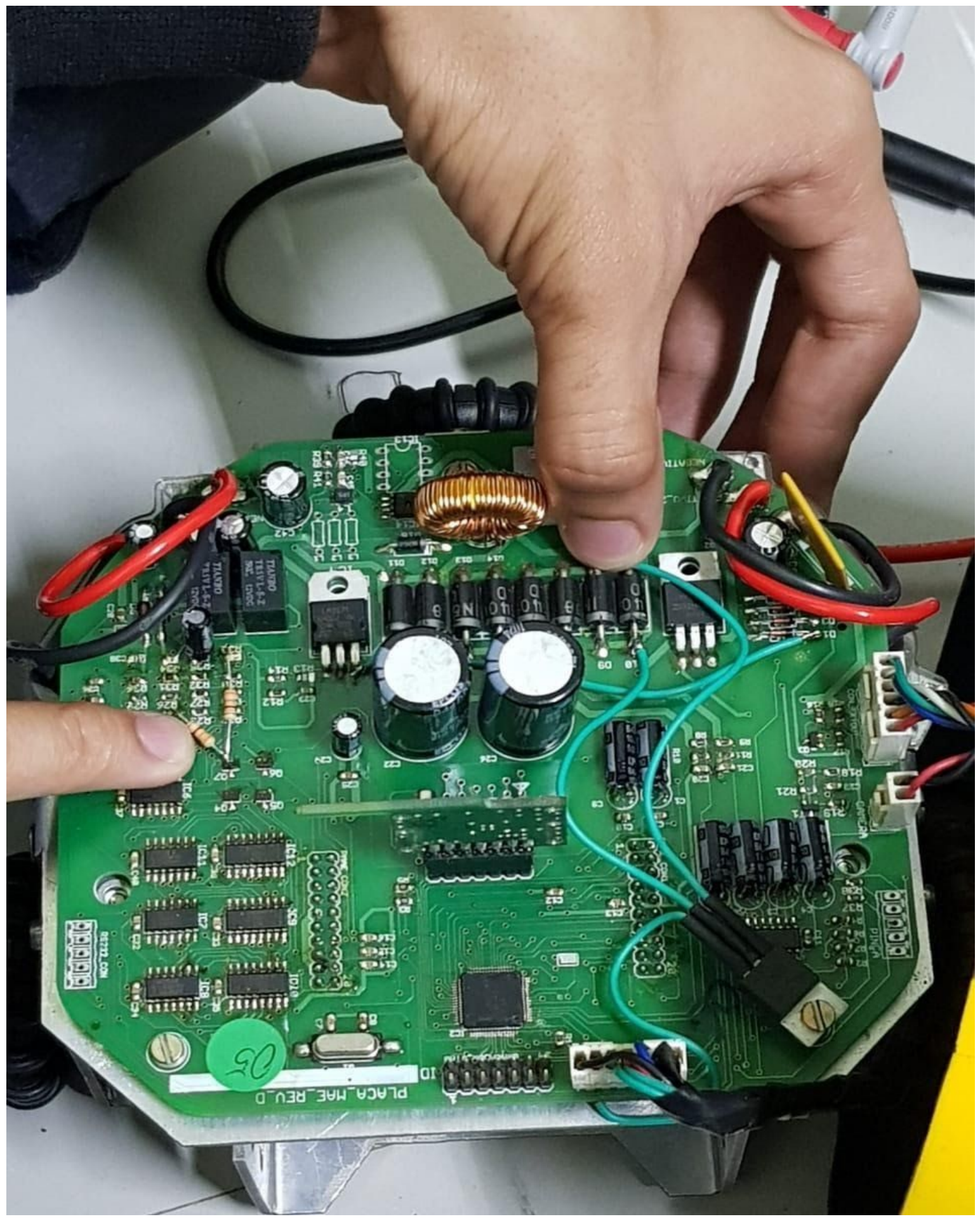

Figura 4: Exibição de algumas peças danificadas. 


\title{
Evento On-line
}

\section{INTRODUCTION TO ROBOTICS PROJECTS USING THE CURUMIM ROBOT}

\begin{abstract}
Aiming to reduce the dropout rate of the Computer Engineering course at CEFET-MG campus II, COMPET, among some measures, proposed the realization of robotics projects with the students of the first period of the course. Among the chosen projects, Curumim was selected by the group and had prior planning to recover the robot's functioning properly. However, it was not possible to return the robot to operation, but the students received new perspectives on the failures and the possibilities of solutions through them. It was also possible to check the errors with the robot and define a new project as a target.
\end{abstract}

Keywords: COMPET, Robotics, Curumim, Computing. 